\title{
From scribe to YouTuber: A proposal to teach the History of the English Language in the digital era
}

\author{
Paula Rodríguez-Abruñeiras, Jesús Romero-Barranco
}

Department of English and German Philology, Universitat de València, Spain

\begin{abstract}
The present paper deals with a proposal for enhancing students' engagement in the course 'History of the English Language' of the Degree in English Studies (Universitat de València). For the purpose, the traditional lectures will be combined with a research project carried out by groups of students (research teams) in which two digital tools will be used: electronic linguistic corpora and YouTube. Electronic linguistic corpora, on the one hand, will allow students to discover the diachronic development of certain linguistic features by looking at real data and making conclusions based on frequencies by themselves. YouTube, on the other, is a most appropriate online environment where students will share a video lecture so that their classmates can benefit from the research work they did, fostering peer-to-peer learning. The expected results are to make students more autonomous in their learning process, as they will be working on their project from the very beginning of the course; and to engage them more effectively since they will be working in a format that resembles what they do at their leisure time.
\end{abstract}

Keywords: History of the English Language; electronic linguistic corpus; YouTube; peer-to-peer learning; Web 2.0. 


\section{Introduction}

The time devoted in any Spanish degree to the teaching of the History of the English Language (HEL) has been drastically reduced since the adaptation of the high educational degrees to the European Higher Education Area (Bologna Plan). The topics that used to be covered in approximately six courses (both compulsory and elective credits) are now typically condensed into just one. This is an arduous task if we consider the course's chronological scope (usually from the Old English period up to the present-day), its interdisciplinary reach (it deals with phonology, morphology, syntax, external history, etc.; cf. Giancarlo 2017: 59, Hayes and Burkette 2017: 1, or Lanehart 2017: 41, among others), and the time limitations of the semester (barely four months). As a result, it is little wonder that our students perceive the subject as awesome, though in the original meaning of the word: 'Inspiring awe; appalling, dreadful, weird' (Oxford English Dictionary, awesome, adj., 2; cf. Hayes and Burkette 2017: 1).

In this paper we approach the teaching of HEL from the perspective of digital pedagogy (Tyrkkö 2017: 142) by incorporating new technologies into the classroom. The main aim of this proposal is to make our students come to terms with a course that, at least in principle, is no longer appealing to them. Two are the key digital tools that students will use: electronic linguistic corpora and YouTube. The use of corpora for linguistic research can be traced back to the 1960s, but it is in vogue since the 1990s (cf. Tyrkkö 2017: 141). In our proposal of corpus-based learning, we follow Tyrkkö's (2017: 145) teacher-mediated or researchfocused methodologies. Moreover, our students will also use YouTube for presenting their projects.

The paper is organised as follows. Section 2 describes the contents covered in the course together with a timeline; Section 3 focuses on the portfolio task which students should complete by the end of the semester; finally, Section 4 closes the paper with some concluding remarks on the proposal and its implications for the Degree in English Studies at the Universitat de València.

\section{The course structure}

HEL is taught as a compulsory course in the first semester of the third year of the Degree in English Studies at the Universitat de València. One of our major concerns when planning the course was the organisation of the contents. If the subject is divided into periods, then the diachronic perspective of change over time might be lost as the topics discussed would be approached synchronically at different points in time. In turn, if the subject is divided by content (i.e. by different thematic areas, such as phonology, spelling, nominal morphology, external history, etc.), then we might "leave out the people in favor of paradigms and rules" (Kretzschmar 2018: 2). In other words, the student might lose sight of the reasons why, for 
example, a given socio-cultural change (such as the Norman Conquest of England) brought about linguistic consequences (in this case, a contribution to the loss of grammatical case). In the end, the traditional division along the temporal axis has been chosen mainly because that is the organisation proposed by scholars who have deliberated on the same idea (cf. Giancarlo 2017: 61) and the one followed in most grammars (see Freeborn 1992, Baugh and Cable 2002, Cable 2002, Hogg and Denison 2006, Algeo 2010, Millward and Hayes 2012 and Kretzschmar 2018, among many others). However, the portfolio task would still guarantee the diachronic dimension as our students will monitor a given structure across time (cf. Section 3 below). As defended by Tyrkkö (2017: 145), students will undoubtedly benefit from a more traditional teacher-based instruction, but once they have acquired some basic background knowledge, they are ready to become more independent in the process of learning how language changes. To that end, linguistic corpora are a suitable tool as they allow students to make first-hand observations about linguistic usage and change, and "the experience of discovering the past for oneself can be a memorable one, and it almost certainly leaves a more lasting memory for most than simply reading a fact from a book or hearing it in a lecture” (Tyrkkö 2017: 149). Nevertheless, thoughtful planning is required beforehand. Based on the academic planner for 2017/2018 Autumn semester, our proposal is divided into 27 sessions. The contents per session would be organised into five main units, as shown in Table 1 below.

Table 1. Academic planner for HEL

\begin{tabular}{ccccccc}
\hline $\begin{array}{c}\text { Unit 1. } \\
\text { Intro }\end{array}$ & $\begin{array}{c}\text { Project } \\
\text { assignment }\end{array}$ & Unit 2. OE & Unit 3. ME & Unit 4. ModE & $\begin{array}{c}\text { Unit 5. } \\
\text { PDE \& } \\
\text { NE }\end{array}$ & $\begin{array}{c}\text { YouTube } \\
\text { sessions }\end{array}$ \\
\hline Ss 1-3 & S 4 & Ss 5-12 & Ss 13-18 & Ss 19-23 & $\begin{array}{c}\text { Ss 24- } \\
25\end{array}$ & Ss 26-27 \\
\hline
\end{tabular}

Unit 1: The first unit presents the students with some preliminary notions necessary to understand the development of the English language. These include concepts such as grammaticalisation, lexicalisation, syntactic reanalysis, proto-Indo-European, etc.

Units 2-4: The core of the course is the discussion of the main linguistic and socio-cultural features of the Old, Middle and Modern English periods (OE, ME and ModE, respectively). The three units follow a similar division: first, the external history of the period is presented, and then attention turns to the discussion of the main linguistic features of the time. The six most important linguistic aspects considered are orthography, phonology, morphology of the noun phrase, morphology of the verb phrase, syntax and lexis. The number of sessions gradually decreases from one period to the next as the degree of difficulty also declines. Thus, OE, which is the most opaque and unknown period for students, deserves at least eight sessions. In turn, five sessions are enough for ModE as the language is already transparent 
for the students and most of the relevant changes have already taken place. The examples used to illustrate the theoretical explanations include some of the most relevant literary works from each period (Beowulf for OE, The Canterbury Tales for ME and some plays by Shakespeare for ModE), but also texts from the Helsinki Corpus of English Texts: Diachronic and Dialectal (HC) (cf. Section 3.1 below). We will also make our students work with digitised manuscripts such as the Digital Vercelli Book so that they get to know how real manuscripts looked like.

Unit 5: This unit is primarily concerned with the English spoken in different parts of the world to make our students aware of the existence of other varieties beyond the two supranational ones (i.e. British and American English). The study of variation in the New Englishes (NE) is increasingly becoming the object of research in recent times (see Mesthrie and Bhatt 2008, and Seoane and Suárez-Gómez 2016, among many others), and it also deserves a place in the Degree in English Studies. In this case, the examples are taken from the ICE corpora, which include texts from a wide range of countries (e.g. Canada, Hong Kong, India, or The Philippines, among others; cf. Section 3.1).

Sessions 4, 26 and 27 have a different dynamic. Session 4 is entirely devoted to the presentation of the portfolio task (for more information on the task, see Section 3 below); and in sessions 26-27 the videos prepared by the students are watched in class.

\section{An up-to-date proposal}

The present section deals with a teaching proposal in which the use of electronic corpora and Web 2.0 strategies will be incorporated in an attempt to make materials more attractive to students who are described as "Millennials", among other labels (Tapscott 1997; Oblinger 2003; Duffy 2008). They constitute a generation surrounded by digital stimuli since their birth and, as young adults, are in constant interaction with technology and the internet. Thus, students are used to playing video-games online with their friends while they stream on YouTube or Twitch; they follow celebrities and influencers who upload videos on a daily basis; and, instead of a book or even Google, they look for help on YouTube whenever they need it. These leisure activities, among many others, have turned paper-based materials, PDF files as well as PowerPoint/Prezi presentations into something obsolete and static that does nothing but contribute to the students' apathy for a tough and dense subject such as HEL.

\subsection{English historical corpora in the classroom}

Irrespective of the approach taken by teachers in the teaching of HEL (either dividing the contents by period or by linguistic features), the ultimate objective of the subject is to focus on language change over time. To achieve this, historical corpus linguistics makes use of historical corpora, which are collections of texts especially designed to represent a particular 
stage in the history of English so that linguistic change can be assessed (Claridge 2008: 242). The use of historical corpora has enhanced the potential of historical linguistics as: 1) computer-based historical corpora offer the linguist large amounts of data as well as tools for dealing with it (word-counts, frequencies, statistics, etc.); 2) statistical analyses contribute to a better understanding of the way in which linguistic change takes place, either supporting or refuting previous linguistic theories; 3) historical linguistics has adopted more functional approaches, which assess how language structure is affected by language use; and 4) less canonical texts have been made available in corpus format so that genres or text types that had not been paid the attention they deserve can now be used as sources of evidence for linguistic analyses (Curzan 2008: 1091).

It makes sense, therefore, to incorporate corpora to HEL teaching, as scholars in the field have been using electronic corpora for research since the early 1990s. ${ }^{1}$ This way, students will not only learn about diachronic processes directly from the source, but also will be trained in historical corpus linguistics by means of real fieldwork. As stated by Curzan, "corpora open the possibility of providing students with an individual, interactive way to investigate larger historical changes, be they syntactic, morphological, semantic, or orthographic” (2000: 81). In order to do this, at the beginning of the course students are divided into small research teams tasked with studying the diachronic development of a particular linguistic feature over time. Depending on the nature of the linguistic feature, these studies will make use of different available corpora so that they can look at different parameters such as sociolinguistic profiles and register/textual variation, among others. This way, students will step into the role of researchers and, consequently, the learning process will be far more engaging and their discoveries and conclusions more significant. The following corpora will be used:

1. HC - Helsinki Corpus of English Texts: Diachronic and Dialectal (c. 730-1710).

2. PCEEC - Parsed Corpus of Early English Correspondence (1410-1681).

3. ICE - International Corpus of English (Present-day varieties of English).

In order to retrieve data from these corpora, students will use AntConc 3.2.4 (Anthony 2014), a freeware corpus analysis toolkit for linguistic research. The use of these corpora in the classroom will show students how scholars carry out their studies and, more importantly, will allow them to witness the diachronic development of multiple linguistic processes/features by themselves with real sources.

\footnotetext{
${ }^{1}$ According to Tyrkkö, "despite the importance of corpus evidence to research, when it comes to teaching the History of English most textbooks do not as a rule provide quantitative corpus evidence and many teachers prefer assigning canonical set texts rather than making corpora available to students directly” (2017: 142).
} 


\subsection{Turning students into YouTubers}

Simultaneously with the research project, each team will record a video lecture in which they will present their final project with the structure of a research paper (introduction, methodology, analysis and conclusions). For the purpose, each research unit will create a YouTube channel in which they will upload their video. In addition to the required video, students will be allowed to upload a video in which they present the team as well as any other video which they consider relevant for their project. In a nutshell, their YouTube channel will constitute an online space in which they will upload a project in video format and as many supporting materials as they consider necessary. The goal is to offer a thorough explanation of their assigned topic so that their classmates can benefit from the work done.

The application of YouTube videos to the course has a threefold objective: 1) students will be autonomous in their learning process since they will know their team's objective from the very beginning and, thus, lectures and secondary readings will be more appealing to them; 2) once they finish their videos, all students will be able to watch them, and the diachronic development of everything contained in the course will be available online for students; and 3) peer-to-peer learning will take place inasmuch as students will be able to learn about diachronic phenomena explained by their classmates.

The methodological part is of paramount importance in this teaching strategy as the two teachers in charge of the subject will have to deal with approximately 12 groups of 5 students (60 students altogether). This means c. 12 research projects displayed in 12 YouTube channels. The following subsequent stages will be completed by students:

1. Project assignment. In the fourth session of the course, each group will be assigned a topic and a corpus to be used as the input. After that, the teachers will explain the theoretical background for each period in the following sessions, and the students should, with that theoretical frame in mind (but also with additional secondary material uploaded to Aula Virtual), trace the diachronic development of a given linguistic feature (e.g. the grammaticalisation of while from noun to conjunction; cf. Brems and Hoffmann 2017: 139) across time.

2. Meetings with the teachers will be arranged after units 2,3 , and 4 so that the students can report on their ongoing project. Thus, the teachers will monitor the process and correct methodological/content mistakes.

3. Along similar lines, each research group will be assigned a teaching assistant (TA) once the project is written by the research teams and proofread by the two teachers in charge. TAs will help improve our students' expression and pronunciation.

4. Research teams have roughly two weeks to record their videos and upload them to their YouTube channel. The format in which they present their project is optional. Different examples will be made available so that research teams can choose. 
5. The videos are displayed in class and students can ask questions to the different research teams. At the end of each video, each group should test whether or not their classmates have understood the explanations by means of a quiz, which may take the format of online review games, such as Kahoot or Quizizz. By doing so, students would benefit from the experience of becoming teachers for a day.

\section{Conclusions and implications of our proposal for the Degree in English Studies}

In the sections that precede, a new approach to the teaching of HEL has been proposed trying to pave the way for a change in the perception of the subject on the part of students. The digital methodology here suggested not only involves the use of electronic linguistic corpora (the sine qua non of Historical Linguistics; cf. Tyrkkö 2017: 142), but also the integration of social media (the sine qua non of college students) in the classroom. As a result, many different general and cross-curricular learning competencies of our degree are enhanced thanks to the portfolio task, but special mention must be made of the following: application of ICTs (CG03), team work (CG04), critical thinking and interpretation of data (CB3), transmission of knowledge (CB4) and autonomous learning (CT01). Our students would also benefit from the contact with native speakers during the rehearsal of their videos, something which would no doubt help them improve their pronunciation and their communication skills. Finally, we should not forget that peer learning can help students learn effectively, and giving them the chance to take on the role of the teacher may be highly beneficial for those who will eventually become teachers in the future, which, in a degree like ours, is a very high percentage.

\section{References}

Algeo, J. (2010). The Origins and Development of the English Language, Sixth Edition. Boston: Wadsworth.

Anthony, L. (2014). AntConc 3.2.4: Computer Software. Tokyo, Japan: Waseda University. http://www.laurenceanthony.net/.

Baugh, A.C. \& Cable, T. (2002). A History of the English Language, Fifth Edition. London: Routledge.

Brems, L. \& Hoffmann, S. (2017). Approaches to grammaticalization and lexicalization. In L. Brinton (Ed.), English Historical Linguistics: Approaches and Perspectives (pp. 131157). Cambridge: Cambridge University Press.

Cable, T. (2002). A Companion to Baugh \& Cable's History of the English Language, third edition. London/New York: Routledge. 
Claridge, C. (2008). Historical Corpora. In A. Lüdeling \& M. Kytö (Eds.), Corpus Linguistics: An International Handbook (pp. 242-258). Berlin and New York: Walter de Gruyter.

Curzan, A. (2008). Historical Corpus Linguistics and Evidence of Language Change. In A. Lüdeling \& M. Kytö (Eds.), Corpus Linguistics: An International Handbook (pp. 10911108). Berlin and New York: Walter de Gruyter.

Curzan, A. (2000). English Historical Corpora in the Classroom: The Intersection of Teaching and Research. Journal of English Linguistics 28, 77-89.

Duffy, P. (2008). Engaging the YouTube Google-Eyed Generation: Strategies for Using Web 2.0 in Teaching and Learning. The Electronic Journal of e-Learning 6(2), 119-130.

Freeborn, D. (1992). From Old English to Standard English. London: Macmillan.

Giancarlo, M. (2017). Philology, theory, and critical thinking through the History of the English Language. In M. Hayes \& A. Burkette (Eds.), Approaches to Teaching the History of the English Language (pp. 59-69). Oxford: Oxford University Press.

Hayes, M. \& Burkette, A. (2017). Introduction. In M. Hayes \& A. Burkette (Eds.), Approaches to Teaching the History of the English Language (pp. 1-10). Oxford: Oxford University Press.

Hogg, R. \& Denison, D. (2006). A History of the English Language. Cambridge: Cambridge University Press.

Kretzschmar, W.A. Jr. (2018). The Emergence and Development of English: An Introduction. Cambridge: Cambridge University Press.

Lanehart, S.L. (2017). How is HEL relevant to me? In M. Hayes \& A. Burkette (Eds.), Approaches to Teaching the History of the English Language (pp. 41-55). Oxford: Oxford University Press.

Mesthrie, R. \& Bhatt, R. (2008). World Englishes: The Study of New Linguistic Varieties. Cambridge: Cambridge University Press.

Millward, C.M. \& Hayes, M. (2012). A Biography of the English Language, Third Edition. Boston: Wadsworth.

Oblinger, D. (2003). Boomers, Gen-Xers, and Millennials: Understanding the 'New Students'. EDUCASE 38(4), 36-40.

Seoane, E. \& Suárez-Gómez, C. (Eds.) (2016). World Englishes: New Theoretical and Methodological Considerations. Amsterdam and Philadelphia: Benjamins.

Tapscott, D. (1997). Growing Up Digital: The Rise of the Net Generation. New York: McGraw-Hill.

Tyrkkö, J. (2017). Discovering the past for yourself: Corpora, data-driven learning, and the History of English. In M. Hayes \& A. Burkette (Eds.), Approaches to Teaching the History of the English Language (pp. 141-155). Oxford: Oxford University Press. 